
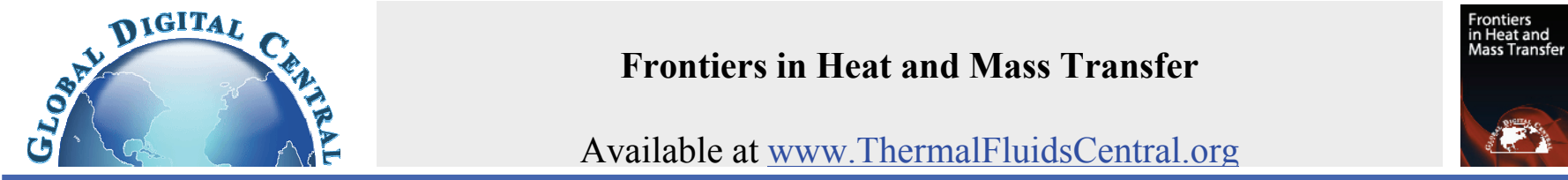

\title{
COMBUSTION EFFICIENCY INSIDE CATALYTIC HONEYCOMB MONOLITH CHANNEL OF NATURAL GAS BURNER START-UP AND LOW CARBON ENERGY OF CATALYTIC COMBUSTION
}

\author{
Shihong Zhang*, Zhihua Wang \\ School of Environment and Energy Engineering, Beijing University of Civil Engineering and Arch., Beijing, China
}

\begin{abstract}
This article discussed exhaust gas temperature and pollutant emissions characteristics of the combustion of rich natural gas-air mixtures in Pd metal based honeycomb monoliths burner during the period of start-up process. The burner needs to be ignited by gas phase combustion with the excessive air coefficient (a) at 1.3. The chemistry at work in the monoliths was then investigated using the stagnation point flow reactor or SPFR. The experimental results in catalytic monolith can be explained from SPFR. The exhaust gas temperature and pollutant emissions were measured by thermocouple $\mathrm{K}$ of diameter 0.5 and the analyser every 1 minute, respectively. Meanwhile combustion efficiency were calculated. Catalytic combustion of natural gas plays an important role for low carbon energy in industrial applications.

Keywords: catalytic combustion; temperature; exhaust gas pollutant emissions; start-up; combustion efficiency.
\end{abstract}

\section{INTRODUCTION}

Rising concentrations of greenhouse gases(GHG) in the atmosphere have been associated with global climate change. This phenomenon, which has resulted in an increase of global mean surface temperature, has serious negative effects on climatic systems, on the natural environment, and upon human society (Solomon et al., 2007). Along with the development of society, vast quantities of these gases have been discharged into the atmosphere-namely carbon dioxide $\left(\mathrm{CO}_{2}\right)$, methane and other non- $\mathrm{CO}_{2}$ gases (Nakata et al., 2011). These emissions are generated primarily from the combustion of fossil fuels, such as petroleum, coal, and natural gas. With climate change threats, the levels of GHG need to be stabilized and eventually reduced. Clearly, our consumption of fossil fuels must decrease, partly due to a limited and uncertain future supply and partly because of undesirable effects on the environment (International Energy Agency, 2009).

Essentially, a sustainable supply of energy for societal needs must be secured in long-term for our future generations. With well-founded scientific supports and international agreement, renewable energy sources must be urgently developed and widely adopted to meet environmental and climate related targets and to reduce our dependence on oil and secure future energy supplies (Sawangphol and Pharino (2011). To reduce $\mathrm{CO}_{2}$ emissions into the atmosphere, alternatives for " $\mathrm{CO}_{2}$-free" utilisation of natural gas should be developed. Natural gas is recognized as the fossil fuel causing least damage to the environment. This is because it is clean, has a low carbon ratio (Lynum, 1997).

Catalytic combustion has so far found limited applications. However, the need for distributed and portable power generation that relies on modularity and small scales may render catalytic combustion an appealing technology (Deshmukh and Vlachos, 2007). Catalytically assisted combustion can greatly improve the performance of combustion devices and aid the development of new energy generation technologies (Wiswall et al., 2009). Catalytic combustion in small devices is preferred because the reaction occurring at much lower temperatures and being sustained at much leaner fuel/air ratios compared to homogeneous combustion, thereby easing the design constraints of the system (Bijjula and Vlachos, 2011).

Catalytic combustion can be applied in commercial class gas engines to reduce NOx emission and micro gas turbines to improve flame stability (Yuan et al., 2008). When used in burners, these oxidation catalysts increase the stability of ultra-lean combustion while generating near-zero pollutant emissions, thus offering a sound alternative to less stable low-NOx combustion technologies such as lean burn (Dupont et al., 2000). Introduction of the hybrid catalytic combustor concept has also been able to overcome the material constraints associated with fully catalytic combustors to meet the higher turbine inlet temperatures (Andrae et al., 2005).

In recent years, research efforts have focused on portable, hydrocarbon-fueled power generating devices. Catalytic microreactors, in particular, have received a lot of attention due to their operational benefits at small scales. While all such studies, both numerical and experimental, have provided valuable insight on the steady-state behavior of catalytic micro-combustors, studies on their transient behavior and in particular on the crucial issue of micro-reactor start-up remain limited (Karagiannidis and Mantzaras, 2009).

An extensive experimental investigation was carried out to investigate transient behavior of catalytic combustion burner during start-up process. Exhaust gas temperature and pollutant emissions could be measured by thermocouple $\mathrm{K}$ of diameter 0.5 and the analyser every 1 minute, respectively. Gas temperature and emissions mechanism with the increasing of time during start-up process were studied. At the same time, combustion efficiency inside catalytic honeycomb monolith channel of natural gas burner VI was calculated. 


\section{EXPERIMENTAL SET-UP}

Figure 1 illustrates the exhaust gas analysis system of catalytic combustion burner, The square honeycomb monoliths were $150 \mathrm{~mm}$ wide in sides of the square and $20 \mathrm{~mm}$ long, with square-shaped cells which sectional area was $1 \mathrm{~mm} \times 1 \mathrm{~mm}$. The support for all the monoliths tested here was cordierite. The four square catalytic honeycomb monoliths were installed in the burner each time. The lengths of catalytic honeycomb monoliths were $20 \mathrm{~mm}$ for the catalytic combustion burner.

In order to decrease the temperature of mixtures in chamber connected with the monolith's entrance, the $20 \mathrm{~mm}$ long blank monoliths were inserted between the chamber and the Pd based catalytic monolith's entrance as assembly of monolith. At the chamber outlet we recorded length of catalytic honeycomb monolith as zero as shown in Fig. 2.

In the experiment, the reactant gas feeds of natural gas and air were regulated via GMS005 0BSRN200000 natural gas meter and CMG400A080100000 air meter with $0 \sim 50 \mathrm{~L} / \mathrm{min}$ and $0 \sim 80 \mathrm{~m} 3 / \mathrm{h}$ of full-scale ranges, respectively. The two meters were provided electric current through manostat.

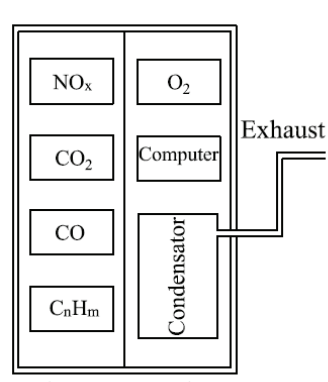

Exhaust gas analyser

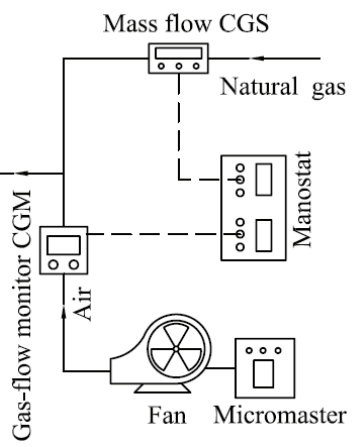

Fig. 1 Exhaust gas analysis system of catalytic combustion burner VI

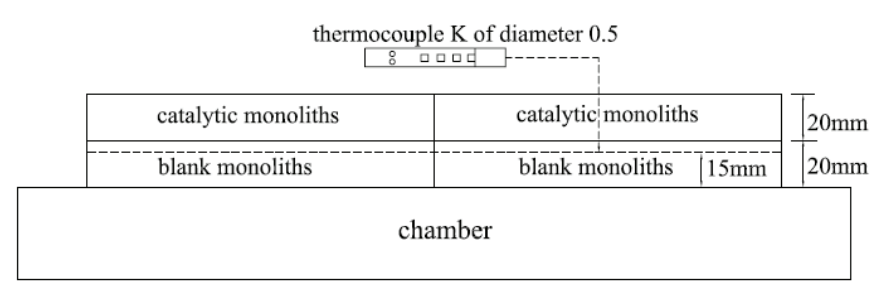

Fig. 2 Schematic of exhaust gas temperature measurement of catalytic honeycomb channel.

In the process of ignition, we need to swept the inside of burner by air for five minutes to ensure that there was no residual natural gas. The burner must be ignited by gas phase combustion with the excessive air coefficient (a) at 1.3 during the period of start-up process under the condition of invariable natural gas flow rate $(9.5 \mathrm{~L} / \mathrm{min})$. The blue flame was achieved above the monolith and gradually disappeared when the catalyst started glowing red internally as the temperatures inside the monolith increased Then the excessive air coefficient(a) should be adjusted to 2.0 under fuel lean condition while the catalyst reached steady state.

Exhaust gas temperature inside catalytic honeycomb channel within the first $15 \mathrm{~mm}$ of monolith could be measured by thermocouple $\mathrm{K}$ of diameter 0.5 which sensor was supposed to measure temperature for transient changes, and pollutant emissions could be measured by the $\mathrm{NO}-\mathrm{NO}_{2}-\mathrm{NOx}$ thermo electron analyser, $\mathrm{CO} / \mathrm{CO}_{2}$ thermo electron analyser every 1 minute. At the same time we observed and recorded the data.

The emissions characteristics of the combustion of fuel-rich mixtures of methane (main composition of natural gas) and air were studied in steady-state conditions in a catalytic honeycomb monolith burner. In order to investigate the parameters controlling the kinetics and products selectivities of the heterogeneous (solid-gas) oxidation of methane on a 'model' noble metal, and the homogeneous ignition inhibition phenomenon, fundamental work on a small-scale reactor was carried out (the stagnation point flow reactor or SPFR). The combustion of rich $\mathrm{CH}_{4} / \mathrm{O}_{2} / \mathrm{N}_{2}$ mixtures on a polycrystalline platinum foil in a stagnation point flow reactor at atmospheric pressure and in steady-state was investigated. For the SPFR, Fig. 3 showed the diagram of the reactor.

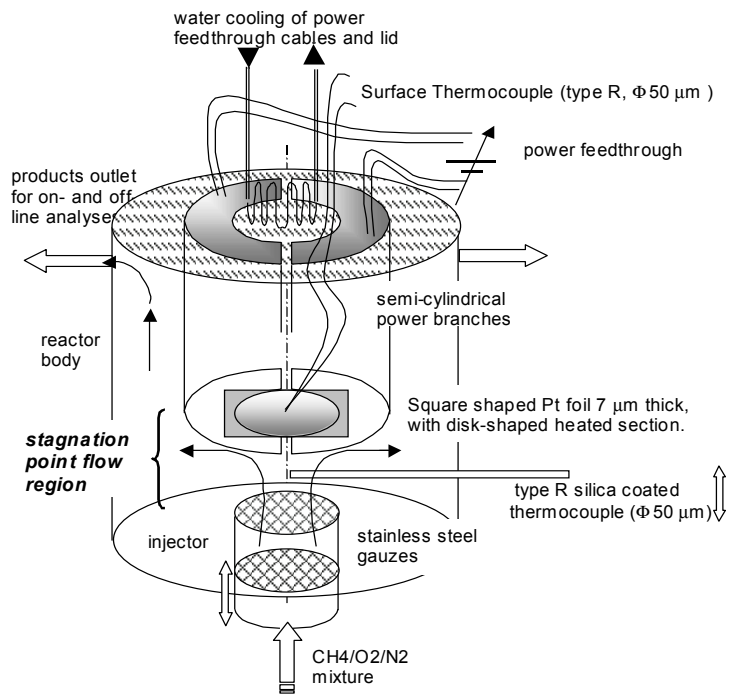

Fig. 3 Stagnation point flow reactor

\section{EXPERIMENTAL RESULT AND DISCUSSION}

\subsection{Mechanism of catalytic combustion of methane}

The following equations (1) and (2) for the percent fuel conversion and the selectivity of products SELk for the species ' $k$ ' were derived (on a mol basis) (Dupont et al., 2001):

$C V_{C H_{4}}=-100 \frac{F_{C_{4}} C_{S}+\int_{0}^{L} W_{C H_{4}} \dot{\omega}_{C H_{4}} C d x}{\rho_{0} Y_{C_{4}, 0} U_{0}}$

$S E L_{k}=-100 \frac{\frac{F_{k}}{W_{k}} C_{S}+\int_{0}^{L} \dot{\omega}_{k} C d x}{\left[\frac{F_{C H_{4}}}{W_{C H_{4}}} C_{S}\right]+\int_{0}^{L} \dot{\omega}_{C H_{4}} C d x}$

where $W_{k}$ is the molar mass of the species $\mathrm{k}, \dot{\omega}_{k}\left(\right.$ in $\left.\mathrm{mol} / \mathrm{cm}^{3} \cdot \mathrm{s}\right)$, is the molar production rate of $\mathrm{k}, F_{k}\left(\right.$ in $\left.\mathrm{kg} / \mathrm{cm}^{2} \cdot \mathrm{s}\right)$, is the mass flux of $\mathrm{k}$ at the foil surface, the subscript 0 means 'at the injector outlet' $(x=0$ $\mathrm{cm}$ ). $\rho_{0}, Y_{\mathrm{CH}_{4} 0}$, and $U_{0}$ are the gas density, fuel mass fraction and axial velocity at the injector outlet, their product being the mass flux of fuel in the reactor. The coefficient $\mathrm{C}$ is a correction factor which accounts for a slight radial expansion of the control volume used to perform the species balances in the calculation of the fuel conversion and products selectivities. This control volume, originally cylindrical with a radius $\mathrm{r}$ at its basis (location of injector) increasing to a radius $r_{s}^{*}=r\left(1+K L T_{s} / T_{j}\right)$ at the catalytic surface. Cs corresponds to $\mathrm{x}=\mathrm{L}=$ $1 \mathrm{~cm}$, i.e, the value of $\mathrm{C}$ at the foil surface. For our SPFR, we show the conversion curves obtained this time without correction factor, therefore it is one. The proportionality constant $\mathrm{K}$ was chosen to match the predicted fuel conversion of a sample point with its corresponding experimental value.

In order to describe the foil condition for each experiment, two parameters were varied in order to investigate their effects on the fuel conversions and $\mathrm{CO}$ selectivities; these are: 
1. The fuel mixture strength by varying the parameter $\alpha=$ $\dot{V}_{\mathrm{CH}_{4}} /\left(\dot{V}_{\mathrm{CH}_{4}}+V_{\mathrm{O}_{2}}\right)$, where $\dot{V}_{k}$ is the input volume flow rate of the relevant species $\mathrm{k}, \alpha$ was varied from 0.35 to 0.58 .

2. The $\mathrm{N}_{2}$ the mol fraction of nitrogen gas in the inlet mixture, $\mathrm{XN}_{2}$

$$
=\left(\dot{V}_{N_{2}}+0.79 \dot{V}_{\text {air }}\right) / \dot{V}_{\text {tot }} \text {. }
$$

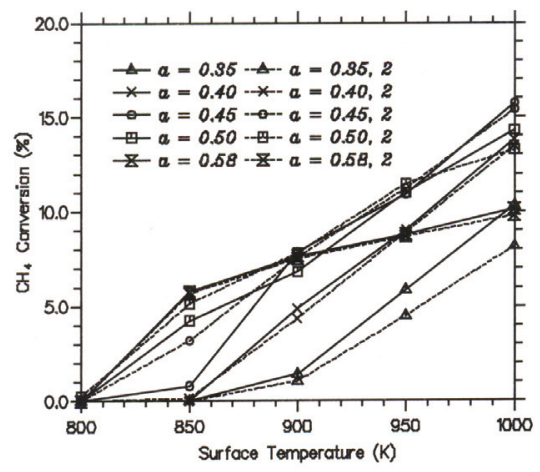

(a)

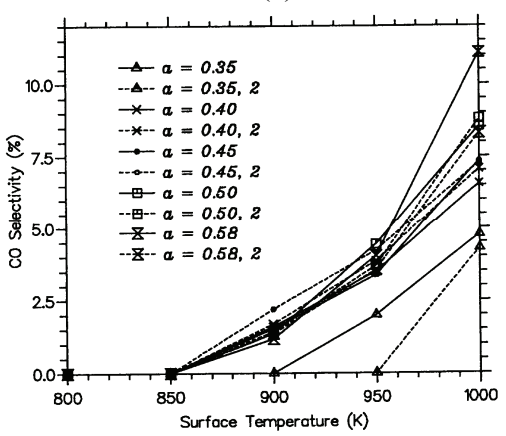

(b)

Fig. $4 \mathrm{CH}_{4}$ conversions inhibition of gas phase ignition phenomenon and $\mathrm{CO}$ selectivities.

Figure 4 show the $\mathrm{CH}_{4}$ conversions inhibition of gas phase ignition phenomenon, as will be seen later, and $\mathrm{CO}$ selectivities for the fuel-rich concentrations of $\alpha(0.35,0.4,0.45,0.5$ and 0.58$)$ and $\mathrm{XN}_{2}(0.91)$, i.e. conditions of partial oxidation on $\mathrm{Pt}$ foil for the SPFR. The $\mathrm{CH}_{4}$ conversion increases with an increase in temperature for the same value of the fuel mixture strength $(\alpha)$.

The main results from these runs are the large $\mathrm{CO}$ selectivities (more than $10 \%$ ) obtained at low catalyst temperatures $(800-1000 \mathrm{~K}$ ). No amounts of $\mathrm{C}_{2} \mathrm{H}_{4}$ and $\mathrm{C}_{3} \mathrm{H}_{8}$ were detected and negligible concentrations of $\mathrm{C}_{2} \mathrm{H}_{6}$ were detected (lower than $8 \mathrm{ppm}$ ).

\subsection{Experimental results}

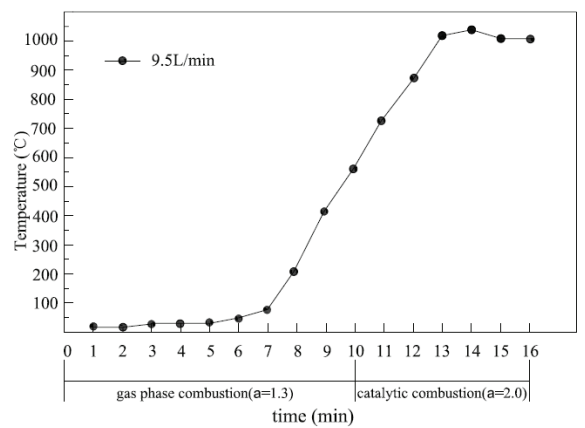

Fig. 5 Exhaust gas temperature in catalytic combustion burner VI during the start-up process with the passage of time (a is excessive air coefficient).
Under the condition of invariable natural gas flow rate $(9.5 \mathrm{~L} / \mathrm{min})$, the experiment was run for 16 minutes. At the time of the ignition we recorded it as zero at the open end of monolith which was connected with pipes of analysers.

Figure 5 plots exhaust gas temperature inside catalytic honeycomb monolith channel of natural gas burner between 0 and 16 minutes. As we can see from the profiles, exhaust gas temperature ascended gradually with the passage of time firstly, then gas temperature was stable when the time reached 13 minutes. The highest temperature among all the time was measured at 14 th minute which was $1080^{\circ} \mathrm{C}$.

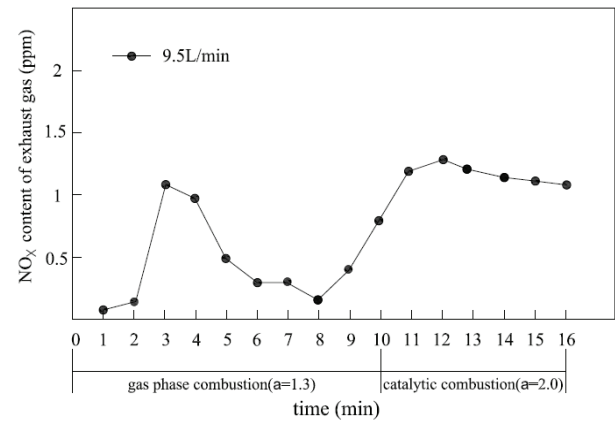

(a) $\mathrm{NO}_{\mathrm{X}}$ content of exhaust gas

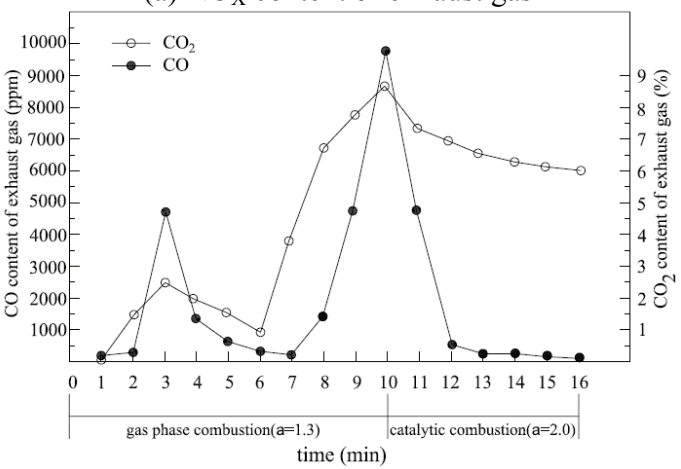

(b) $\mathrm{CO}$ and $\mathrm{CO}_{2}$ content of exhaust gas

Fig. 6 Exhaust gas pollutant emissions in catalytic combustion burner VI during the start-up process with the passage of time (a is excessive air coefficient).

Figure 6 plots exhaust gas pollutant emissions in catalytic combustion burner VI during the start-up process as time went on. It was seen from Fig. 6(a) that the emission of NOx increasing during the first portion of gas combustion between 0 and 3 minutes at the open end of burner was detected. Then NOx decreased between 3 and 8 minutes. Because the flame appeared during the early period of start up process inside honeycomb monolith channels. Then the combustion flame was disappeared gradually with the decreasing NOx after 3 minutes. After 8 minutes, the emission of NOx was rising again, at the same time the temperature was increasing quickly inside honeycomb monolith channels. However the channel temperature was too low to product a larger number of NOx (below 2 ppm).

In this gas phase combustion of rich natural gas /air mixtures, about 7 percent of natural gas/air mixtures was used in the process of start-up. The total volume flow rate of reactants was the same as that of products via the reaction $\mathrm{CH}_{4}+2 \mathrm{O}_{2}=\mathrm{CO}_{2}+2 \mathrm{H}_{2} \mathrm{O}$. So the percentage of $\mathrm{CO}_{2}$ should remain unchanged according to the excessive air coefficient. As shown in Fig. 5(b) the percentage of $\mathrm{CO}_{2}$ was about $8 \%$ without vapor by the $\mathrm{CO}_{2}$ analyzer inside honeycomb monolith channels during the gas phase combustion. When the burner reached the state of catalytic combustion, the percentage of $\mathrm{CO}_{2}$ was decreased to about $6 \%$ approximately. It was clear that $\mathrm{CO}_{2}$ measurement was sure to the above analysis. 
It was also shown in Fig. 6(b) that theCO content of exhaust gas ascended dramatically as time went on between 0 and 10 minutes. During the start-up process, there were CO selectivities for the fuel-rich concentrations of a (1.3) (conditions of partial oxidation). The main results from these runs were that the large $\mathrm{CO}$ selectivities obtained at low catalyst temperatures inside honeycomb monolith channels. When the burner reached the state of catalytic combustion, the $\mathrm{CO}$ content of exhaust gas dropped to near zero.

$\mathrm{CO}$ and $\mathrm{CO}_{2}$ were increasing during the first portion of gas combustion due to the appeared flame influence and then it decreased with disappeared flame between 3 and 7 minutes. Also $\mathrm{CO}$ and $\mathrm{CO}_{2}$ concentrations had been significantly diluted in 7 minutes due to existing the air in the pipes. After 7 minutes exhaust gas concentrations were distributed all of the pipes.

From the chemical kinetics it can be seen the large CO selectivities for the fuel-rich concentrations. After local catalytic ignition, a steady state was sure to be reached under fuel lean condition.

The exhaust gas content was shown in table 1 between 11 minutes and 16 minutes when the catalyst reached the steady state.

It was shown that these oxidation catalysts increased the stability of ultra-lean combustion while generating near-zero pollutant emissions. The temperature inside the monoliths channels indicated that the catalyst's role was to enable the ignition of nature gas mixtures below flammability limits, to ensure the complete oxidation of the nature gas to $\mathrm{CO}_{2}$ via surface reactions in the steady state.

Table 1 Exhaust gas content $(9.5 \mathrm{~L} / \mathrm{min})$

\begin{tabular}{cccc}
\hline Time $(\min )$ & $\begin{array}{c}\mathrm{C}_{\mathrm{n}} \mathrm{H}_{\mathrm{m}} \\
(\mathrm{ppm})\end{array}$ & $\begin{array}{c}\mathrm{CO} \\
(\mathrm{ppm})\end{array}$ & $\begin{array}{c}\mathrm{CO}_{2} \\
(\%)\end{array}$ \\
\hline 11 & 5.22 & 5088 & 7.4 \\
12 & 5.03 & 830 & 7 \\
13 & 4.25 & 145 & 6.7 \\
14 & 4.22 & 162 & 6.3 \\
15 & 4.14 & 6.06 & 6.2 \\
16 & 4.27 & 5.41 & 6 \\
\hline
\end{tabular}

\subsection{Calculation of combustion efficiency during the start-up process.}

It was evidenced that the catalytic combustion efficiency was almost close to $100 \%$. But there were a lot of $\mathrm{CnHm}$ and $\mathrm{CO}$ from the exhaust gas in catalytic combustion burner during the start-up process.

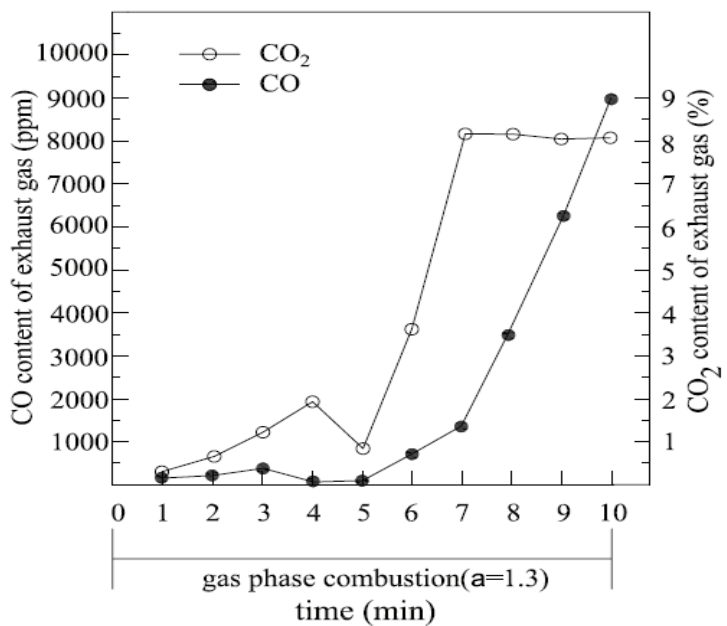

Fig. 7 Exhaust gas pollutant emissions in catalytic combustion burner VI during the start-up process with the passage of time (a is excessive air coefficient).
It was proved that gas-phase combustion had not been oxidized completely and its combustion efficiency should be calculated.

The experiment of gas-phase combustion is run for 10 minutes at an invariable natural gas flow rate of $10 \mathrm{~L} / \mathrm{min}$. At the time of ignition we recorded it as zero.

Figure 7 plots the content of $\mathrm{CO}$ and $\mathrm{CO}_{2}$ in exhaust gas inside catalytic honeycomb monolith channel of natural gas burner VI between 1 and 10 minutes.

The un-burnt $\mathrm{CnHm}, \mathrm{CO}$ and $\mathrm{CO}_{2}$ content of exhaust gas inside honeycomb monolith channels was listed in Table 2.

Table 2 Exhaust gas content $(10 \mathrm{~L} / \mathrm{min})$

\begin{tabular}{llll}
\hline Time(min) & $\begin{array}{l}\mathrm{CnHm} \\
(\mathrm{ppm})\end{array}$ & $\begin{array}{l}\mathrm{CO} \\
(\mathrm{ppm})\end{array}$ & $\begin{array}{l}\mathrm{CO}_{2} \\
(\%)\end{array}$ \\
\hline 1 & 3110 & 86.6 & 0.66 \\
2 & 6450 & 334 & 0.83 \\
3 & 13550 & 505 & 1.75 \\
4 & 13900 & 40.1 & 2.44 \\
5 & 10500 & 63.5 & 1.27 \\
6 & 3100 & 552 & 3.8 \\
7 & 470 & 1430 & 8.3 \\
8 & 96 & 3580 & 8.3 \\
9 & 12.8 & 6330 & 8.1 \\
10 & 6.32 & 9060 & 8.2 \\
\hline
\end{tabular}

The content of $\mathrm{CO}$ in gas-phase combustion was higher than that of catalytic combustion. The maximum of $\mathrm{CO}$ emission reached about $9060 \mathrm{ppm}$, which indicated that natural gas of gas-phase combustion hadn't been oxidized completely.

It was revealed that the content of $\mathrm{CnHm}$ in gas-phase combustion was measured at $13900 \mathrm{ppm} \sim 6.32 \mathrm{ppm}$. After an interval of 4 minutes $\mathrm{C}_{\mathrm{n}} \mathrm{H}_{\mathrm{m}}$ was decreased rapidly with the passage of time. It proved that the conversion of gas-phase combustion was lower than that of catalytic combustion.

As the main composition of natural gas was methane, the chemical reaction equation is ( 3 ) in the following:

$\mathrm{CH}_{4}+2 \mathrm{O}_{2}=\mathrm{CO}_{2}+2 \mathrm{H}_{2} \mathrm{O}$

$\mathrm{CO}$ was a kind of intermediate which was generated during combustion of hydrocarbon. The number of $\mathrm{C}$ atom remained unchanged in the reaction process. The total volume of $\mathrm{CO}$ and $\mathrm{CO}_{2}$ was the same as that of $\mathrm{CH}_{4}$ via the reaction equation (3) $\left(\mathrm{V}_{\mathrm{CO}}+\mathrm{V}_{\mathrm{CO} 2}=\mathrm{V}_{\mathrm{CH} 4}\right)$. The volume of methane was given $1 \mathrm{Nm} 3\left(\mathrm{~V}_{\mathrm{CH} 4}=1\right)$. According to equation (4), the volume of $\mathrm{CO}$ and un-burnt $\mathrm{CH}_{4}$ was alculated as:

$$
\left\{\begin{array}{l}
V_{C O}+V_{C O_{2}}=1 \mathrm{Nm}^{3} \\
\frac{V_{C O}}{V_{f}^{d}}=\gamma_{C O} \\
\frac{V_{C O_{2}}}{V_{f}^{d}}=\gamma_{C O_{2}} \\
\frac{V_{C H_{4}}^{1}}{V_{f}^{d}}=\gamma_{C H_{4}}^{1}
\end{array}\right.
$$

where $\mathrm{V}_{\mathrm{CO}}$ and $\mathrm{V}_{\mathrm{CO} 2}$ are the volume of $\mathrm{CO}$ and $\mathrm{CO}_{2}$ in exhaust gas $\left(\mathrm{m}^{3}\right)$, respectively. $\mathrm{V}_{\mathrm{f}}^{\mathrm{d}}$ is the total volume of exhaust gas. $\gamma_{\mathrm{CO}}$ and $\gamma_{\mathrm{CO} 2}$ are ratio of $\mathrm{CO}$ volume and $\mathrm{CO}_{2}$ volume to that of exhaust gas, respectively. $\mathrm{V}_{\mathrm{CH} 4}{ }^{1}$ is the volume of un-burnt $\mathrm{CH}_{4}$ in exhaust gas $\left(\mathrm{m}^{3}\right) . \gamma_{\mathrm{CH} 4}{ }^{1}$ is ratio of $\mathrm{CH}_{4}$ volume to that of exhaust gas. $\gamma_{\mathrm{CO}}, \gamma_{\mathrm{CO} 2}, \gamma_{\mathrm{CH} 4}{ }^{1}$ are measured by the analyser. 
According to equation (5): $1 \mathrm{~m}^{3} \mathrm{CO}$ oxidized completely to $\mathrm{CO}_{2}$ could generate $12644 \mathrm{~kJ}$ heat. It proved that the content of $\mathrm{CO}$ had an important influence for utilization of thermal energy of the fuel.

$\mathrm{CO}+0.5 \mathrm{O}_{2}=\mathrm{CO}_{2}+\Delta T$

Therefore, the heat released of un-burnt $\mathrm{CH}_{4}$ and $\mathrm{CO}$ were calculated as:

$$
\begin{aligned}
& Q_{\mathrm{CH}_{4}}=V_{\mathrm{CH}_{4}}^{1} H_{1} \\
& Q_{\mathrm{CO}}=V_{\mathrm{CO}} H_{2}
\end{aligned}
$$

$\mathrm{H}_{1}$ is net calorific value of methane under standard conditions which is $35.88 \mathrm{MJ} / \mathrm{m} 3 . \mathrm{H}_{2}$ is calorific value of $\mathrm{CO}$ which is $12.64 \mathrm{MJ} / \mathrm{m} 3$.

The following equations (8) for heat released percent of unburnt $\mathrm{CH}_{4}$ and $\mathrm{CO}$ to reactant (natural gas) was derived:

$$
K=\frac{Q_{\mathrm{CH}_{4}}+Q_{\mathrm{CO}}}{V_{\mathrm{CH}_{4}} H_{1}}
$$
(9):

The combustion efficiency of gas-phase was calculated by equation

$$
\eta=1-\frac{V_{\mathrm{CH}_{4}}^{1}+V_{\mathrm{CH}_{4}}^{2}}{V_{\mathrm{CH}_{4}}}
$$

$\mathrm{V}_{\mathrm{CH} 4}{ }^{2}$ is the volume of $\mathrm{CH}_{4}$ which has been used in generating $\mathrm{CO}$. Here $\mathrm{V}_{\mathrm{CH} 4}^{2}=\mathrm{V}_{\mathrm{CO}}$ was known.

According to the aforementioned equations and experimental data( table 1 and table 2), the ratio of heat released of un-burnt $\mathrm{CH}_{4}$ and $\mathrm{CO}$ and combustion efficiency of burner VI were calculated during the start-up process with the passage of time in table 3 .

It was shown from table 3 that part of the energy was wasted in gas combustion which hadn't been oxidized completely. It was proved that the combustion efficiency of gas-phase combustion was lower than that of catalytic combustion by calculated data.

Table 3 Ratio of heat released $(K)$ and combustion efficiency $(\eta)$ during start-up process with the increasing of time.

(a) Exhaust gas content (10L/min)

\begin{tabular}{lll}
\hline Time(min) & \multicolumn{1}{c}{$\mathrm{K}(\%)$} & $\eta(\%)$ \\
\hline 1 & 0.47 & 51.7 \\
2 & 0.75 & 21.4 \\
3 & 0.77 & 22.2 \\
4 & 0.57 & 42.8 \\
5 & 0.82 & 17.5 \\
6 & 0.085 & 90.6 \\
7 & 0.011 & 97.8 \\
8 & 0.016 & 95.9 \\
9 & 0.027 & 92.8 \\
10 & 0.037 & 90 \\
\hline
\end{tabular}

(b) Exhaust gas content $(9.5 \mathrm{~L} / \mathrm{min})$

\begin{tabular}{lll}
\hline Time(min) & \multicolumn{1}{c}{$\mathrm{K}(\%)$} & \multicolumn{1}{c}{$\eta(\%)$} \\
\hline 11 & 0.024 & 93.6 \\
12 & 0.004 & 98.8 \\
13 & 0.001 & 99.7 \\
14 & 0.001 & 99.7 \\
15 & 0 & 100 \\
16 & 0 & 100 \\
\hline
\end{tabular}

For all tests of the catalytic combustion, only extremely small amount of $\mathrm{CO}$, unburned fuel and NOx was detected inside the monolith channels and over the open end of the burner VI. The pollutant emissions can be reduced to a minimum 'near-zero' by the catalytic combustion process.

\section{CONCLUSIONS}

This article discussed exhaust gas temperature and pollutant emissions characteristics of the combustion of rich natural gas-air mixtures in $\mathrm{Pd}$ metal based honeycomb monoliths by means of experiments on a practical burner during the start-up process. It was shown that exhaust gas temperature ascended gradually firstly with the passage of time, then gas temperature was stable when the time reached 13 minutes. There were large $\mathrm{CO}$ selectivities for the fuel-rich concentrations of a (1.3), i.e. conditions of partial oxidation.

Simultaneously, the emission of NOx was near zero inside honeycomb monolith channels as time went on. This article played a key role for further start-up study of catalytic combustion burner.

It proved that the concentration of pollutant emissions in gas-phase combustion was higher than that of catalytic combustion. It was shown that the conversion of gas-phase combustion was lower than that of catalytic combustion by calculation of combustion efficiency.

The depth concern of catalytic combustion of natural gas can restructure energy policy and reduce $\mathrm{CO}_{2}$ emissions.

\section{ACKNOWLEDGMENT}

The project sponsored by the Beijing Municipality Key Lab of Heating, Gas Supply, Ventilating and Air Conditioning Engineering; Funding Project (Building environment and facilities engineering).

\section{NOMENCLATURE}

C correction factor

$C_{m} \quad$ specific heat of water $\mathrm{J} /\left(\mathrm{kg} \cdot{ }^{\circ} \mathrm{C}\right)$

$\mathrm{CV}$ fuel conversion (\%)

$F_{k} \quad$ mass flux of $\mathrm{k}$ at the foil surface, $\left(\mathrm{kg} / \mathrm{cm}^{2} \cdot \mathrm{s}\right)$

$G \quad$ mass flow rate $(\mathrm{kg} / \mathrm{s})$

$H_{h} \quad$ gross calorific value $\left(\mathrm{MJ} / \mathrm{Nm}^{3}\right)$

$L_{g} \quad$ gas volum $\left(\mathrm{m}^{3}\right)$

$M_{r H 2 O} \quad$ molar mass of water $(\mathrm{g} / \mathrm{mol})$

$Q_{i} \quad$ thermal output ( $\left.\mathrm{kW}\right)$

$S E L_{K} \quad$ selectivity of products for the species ' $\mathrm{k}$ '

$U_{0} \quad$ axial velocity 'at the injector outlet' $(\mathrm{x}=0 \mathrm{~cm}),(\mathrm{m} / \mathrm{s})$

$V_{g} \quad$ volume of nature gas $\left(\mathrm{Nm}^{3}\right)$

$\dot{V}_{k} \quad$ input volume flow rate of the relevant species k

$Y_{C H 4}, 0$ fuel mass fraction 'at the injector outlet' $(\mathrm{x}=0 \mathrm{~cm})$

$W_{k} \quad$ molar mass of the species $\mathrm{k}$

Greek Symbols

$\rho_{0} \quad$ gas density at the injector outlet' $(\mathrm{x}=0 \mathrm{~cm}),\left(\mathrm{kg} / \mathrm{m}^{3}\right)$

$\eta \quad$ thermal efficiency $(\%)$

$\dot{\omega}_{k} \quad$ molar production rate of $\mathrm{k}\left(\mathrm{mol} / \mathrm{cm}^{3} \cdot \mathrm{s}\right)$

\section{REFERENCES}

Andrae, J.C.G., Johansson, D., Bursell, M., and Fakhrai, R., 2005, "High-Pressure Catalytic Combustion of Gasified Biomass in a Hybrid Combustor," Applied Catalysis A: General, 293, pp. 129 - 136. http://dx.doi.org/10.1016/j.apcata.2005.07.003

Bijjula, K., and Vlachos, D.G., 2011, "Catalytic Ignition and Autothermal Combustion of JP-8 and Its Surrogates over a Pt/c- $\mathrm{Al}_{2} \mathrm{O}_{3}$ Catalyst," Proceedings of the Combustion Institute, 33(2), pp.1801-1807.

http://dx.doi.org/10.1016/i.proci.2010.05.008 
Deshmukh, S.R., and Vlachos, D.G., 2007, "A Reduced Mechanism for Methane and One-step Rate Expressions for Fuel-Lean Catalytic Combustion of Small Alkanes on Noble Metals," Combustion and Flame, 149(4), pp.366-383.

http://dx.doi.org/10.1016/j.combustflame.2007.02.006

Dupont, V., Zhang, S.H., and Williams, A., 2000, "Catalytic and Inhibitory Effects of Pt Surfaces on the Oxidation of $\mathrm{CH}_{4} / \mathrm{O}_{2} / \mathrm{N}_{2}$ Mixtures," Int. J. Energy Res., 2000, pp.1291-1309.

http://dx.doi.org/10.1002/1099-114X(200011)24:14<1291::AID-ER716 $>3.0 . \mathrm{CO} ; 2-\mathrm{F}$

Dupont, V., Zhang, S. H., Williams, A., 2001, "Experiments and Simulations of Methane Oxidation on a Platinum Surface," Chemical Engineering Science, 56 (8), 2659-2670.

http://dx.doi.org/10.1016/S0009-2509(00)00536-4

International Energy Agency. 2009, World Energy Outlook. World Energy Outlook. Paris: The International Energy Agency; pp. 698.

Karagiannidis, S., and Mantzaras, J., "Numerical Investigation of Methane-Fueled, Catalytic Microreactor Start-Up," Paul Scherrer Institute, Combustion Research Laboratory, CH-5232, 2009, Villigen PSI, Switzerland.

http://www.combustion.org.uk/ECM 2009/P810317.pdf

Lynum, S., 1997, "Natural Gas Utilization without $\mathrm{CO}_{2}$ Emissions," Energy Convers. Mgmt., 38, Suppl., pp. S165-S172.
Nakata, T., Silva, D., Rodionov, M., 2011, "Application of Energy System Models for Designing a Low-Carbon Society," Progress in Energy and Combustion Science, 37(4), pp. 462-502.

http://dx.doi.org/10.1016/j.pecs.2010.08.001

Sawangphol, N., and Pharino, C., 2011, "Status and Outlook for Thailand's Low Carbon Electricity Development," Renewable and Sustainable Energy Reviews, 15(1), pp. 564-573.

http://dx.doi.org/10.1016/j.rser.2010.07.073

Solomon, S., Qin, D., Manning, M., Chen, Z., Marquis, M., Averyt, K.B., Tignor M., and Miller, H.L., 2007 Climate Change: The Physical Science Basis, Contribution of Working Group 1 to the Fourth Assessment Report of the Intergovernmental Panel on Climate Change. Cambridge University Press, Cambridge.

Wiswall, J.T., Wooldridge, M.S., and Im, H.G., 2009, “An Experimental Study of the Effects of Platinum on Methane/Air and Propane/Air Mixtures in a Stagnation Point Flow Reactor," Journal of Heat Transfer, 131, 111201

http://dx.doi.org/10.1115/1.3156788

Yuan, T., Lai., Y.H., Chang, C.K., 2008, "Numerical Studies of Heterogeneous Reaction in Stagnation Flows Using One-dimensional and Two-dimensional Cartesian Models," Combustion and Flame, 154, pp. $557-568$.

http://dx.doi.org/10.1016/j.combustflame.2008.06.005 